\title{
Design of green engineered cementitious composites for pavement overlay applications
}

\author{
M.D. Lepech \& G.A. Keoleian \\ Center for Sustainable Systems, University of Michigan, Ann Arbor, Michigan, USA
}

S. Qian* \& V.C. Li

Department of Civil and Environmental Engineering, University of Michigan, Ann Arbor, Michigan, USA

*Now at Microlab, Delft University of Technology, Delft, The Netherlands

\begin{abstract}
The construction, repair and rehabilitation of concrete pavements relies on the production and flow of large quantities of concrete and its constituents. Within the US, nearly 43 megatons of cement are used annually for the construction, repair and rehabilitation of concrete pavements, accounting for over 39 megatons of $\mathrm{CO}_{2}$ emissions. To reduce environmental impact and improve the sustainability of pavement overlay systems, a class of materials called Engineered Cementitious Composites (ECC) has been designed for durable rigid pavement overlays.

ECC overlays are designed to enhance sustainability in two ways. First, "greener" ECC materials incorporate high volumes of industrial wastes including fly ash, ground granulated blast furnace slag (GGBFS), and waste foundry sands and carbon residue to reduce the environmental impacts of material production. Fundamental micromechanics carefully guide the green material design to maintain pseudo-strain hardening material behavior under tension. This ductile behavior is critical to the second mechanism for sustainability enhancement. Through a distinct fracture phenomenon, the ductility of ECC effectively eliminates reflective cracking, a major cause of premature overlay failure, thereby increasing durability and reducing life-cycle maintenance. Experimental and theoretical analyses verify the green material and durable overlay design approaches. Incorporating industrial wastes, over $70 \%$ of ECC virgin constituents have been replaced without reducing critical mechanical performance characteristics. The combination of green raw materials, a 50\% reduction in overlay thickness, and a doubling of service life as compared to concrete overlays, leads to significant sustainability improvements have been achieved. This paper presents the methodology and results of incorporating green cementitious materials design into rigid pavement overlay systems.
\end{abstract}

\section{INTRODUCTION}

The construction and maintenance of streets and highways in the United States alone consumed an estimated 43 million metric tons of cement in 2006 (PCA 2007; vanOss 2007). The production of this cement resulted in the emission of nearly 39 million metric tons of $\mathrm{CO}_{2}$, over 111 thousand metric tons of $\mathrm{NO}_{\mathrm{x}}$, and over 85 thousand metric tons of $\mathrm{SO}_{\mathrm{x}}$. The greater impacts of this consumption, and its related emissions, are becoming increasingly apparent in the form of acid rain, public health, and global climate change.

In developed countries, much of this construction is targeted at maintenance, rehabilitation, and reconstruction of existing highway pavements. Currently, two systems are used for the rehabilitation of existing rigid pavements (i) an unbonded concrete overlay and (ii) a hot mixed asphalt (HMA) overlay. For either of these overlay systems, reflective cracking is often the ultimate failure mode and limits the service life of the overlay (Tayabji et al 1985; NCHRP 1999; Huang 2004). Such reflective cracking is characterized by repeated traffic loads causing new cracks to "reflect" through the new overlay from pre-existing joints or cracks in the substrate. Current techniques to limit reflective cracking include the use of a bondbreaking layer (i.e. HMA) under concrete overlays which relieve stress concentration at the source of reflective cracking, complete rubblization (breaking concrete into aggregate-like particle in situ) of the substrate concrete, or extensive repair of existing pavement deterioration before overlaying. Currently, none of these approaches has been able to effectively eliminate reflective cracking in rigid pavement overlays. 


\subsection{Ductile rigid pavement overlays}

To overcome the fracture-based phenomenon of reflective cracking, a ductile cement-based material is considered. Within the class of high performance fiber-reinforced cementitious composites (HPFRCC), Engineered Cementitious Composite (ECC) has been designed to exhibit ductility more commonly exhibited by ductile metals than brittle cement-based matrices. Developed through micromechanical tailoring of the components (i.e. cement, sand, and fibers), ECC exhibits an ultimate tensile strain capacity of $3 \%-5 \%$, depending on the specific mixture (Li 2003). This tensile ductility, over 300 times that of normal concrete, is realized through the formation of a large number of closely spaced microcracks under load.

Previous laboratory research has investigated the use of ECC material as repair layer over an existing concrete substrate under both monotonic and fatigue loads (Lim \& Li 1997; Kamada \& Li 2000; Zhang \& $\mathrm{Li}, 2002)$. Those researchers found that through a unique "kinking-and-trapping" mechanism, the material's ductility effectively prevents substrate cracks from reflecting through an ECC overlay. Building from these results, Qian (2007) showed that ECC overlays are significantly more effective than unbonded concrete or HMA overlays in reducing reflective cracking, thereby extending the service life of an ECC rigid pavement overlay.

\subsection{Sustainability of ECC overlays}

Numerous researchers have studied the life cycle costs and impacts of pavement systems (i.e. asphalt versus concrete pavement systems) (Horvath \& Hendrickson 1998; Zapata \& Gambatese 2005. Chen et al 2007). Results from these studies have shown that Portland cement concrete pavements exhibit lower energy consumption and related impacts during the first three life cycle stages (extraction of raw material, manufacture, and placement) as compared to asphalt pavements. But energy consumption and emissions throughout service life is heavily dependent upon local parameters, such as traffic volume, truck loads, and climate.

Zhang et al (2007) has looked at the overall sustainability of unbonded concrete overlays, HMA overlays, and ECC overlays using economic, environmental, and social metrics. Zhang et al found that ECC overlays were able to improve the sustainability of rigid pavement overlays by using ECC materials to extend overlay service life and reduce surface roughness thereby improving vehicle fuel economy. Most important among these findings was the large impact that service life and the suppression of reflective cracking failure mechanisms have on overlay system sustainability.

The motivation behind this research is the development of new ECC composites that incorporate large proportions of industrial waste streams for use in rigid pavement overlay applications. These new versions of ECC are controlled to incorporate waste while maintaining high ductility, high fatigue resistance, and the "kinking-and-trapping" mechanism for suppression of reflective overlay cracking.

\section{GREEN ECC MIX DESIGNS}

A total of 14 ECC mixes were designed incorporating a variety of industrial waste streams. These wastes include fly ash from coal-fired thermoelectric power generation, a variety of sands and wastes from metal casting processes, post consumer carpet fibers, wasted cement kiln dust from cement production, and expanded polystyrene (EPS) beads from lost foam foundry operations. The mix proportions and material properties are shown in Table 1. The incorporation of industrial wastes is governed by micromechanical models for the design of ECC materials as described in Lepech et al (2005; 2007).

A set of metrics capturing consumption and environmental impacts was computed for each of the 14 mix designs. These values result from a life cycle inventory assembled for cement-based materials and summarized by Kendall et al (2007). These values are shown in Table 2.

Mix 4 represents an early version of ECC which was not designed specifically for reduced environmental impact. Comparing Mix 4 with Mix 13, the ECC mixture with the lowest environmental impact, significant improvements are apparent. Total energy consumed in production (from raw material extraction through component manufacturing and transportation) is reduced by $58 \% . \mathrm{CO}_{2}, \mathrm{NO}_{\mathrm{x}}, \mathrm{PM}_{10}$, and $\mathrm{SO}_{\mathrm{x}}$ emissions are reduced by $76 \%, 53 \%, 83 \%$, and $71 \%$ respectively. Virgin material consumption is also cut by $74 \%$ through the use of industrial waste streams. As seen in Table 1, only slight tradeoffs in mechanical performance were seen in these substitutions.

\section{ESTIMATION OF SERVICE LIFE}

As noted by Zapata \& Gambatese (2005) and Zhang et al (2007), in order to assess the overall environmental impacts and sustainability metrics of a pavement overlay system, a model for service lifetime is needed. In the case of an ECC overlay, this model is based on the flexural fatigue life of the ECC material. Zhang \& Li (2002), and later Qian (2007), showed experimentally that ECC, when laid over a cracked or damaged pavement substrate, is subjected to flexural fatigue loads until failure. This mechanism is shown schematically in Figure 1.

Based on this failure mechanism, the flexural fatigue behavior of the ECC materials listed in Table 1 


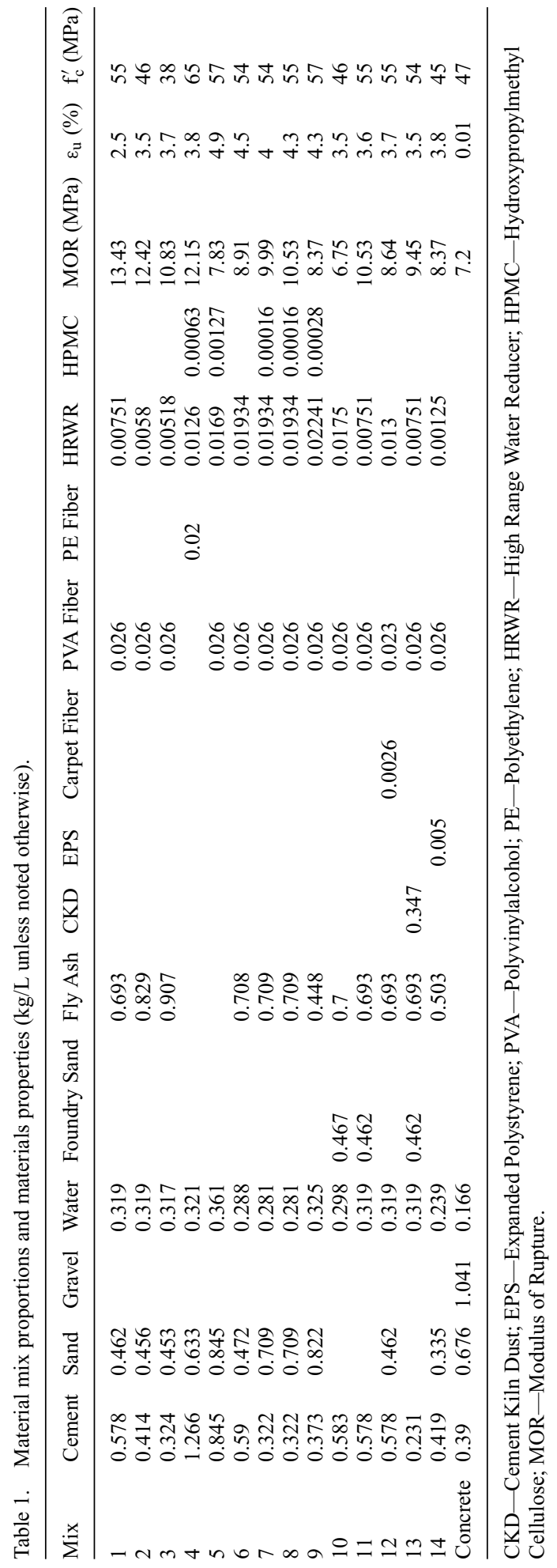

will govern the end of service life of overlays designed with these materials. The flexural fatigue behavior is characterized by S-N curves. To facilitate fatigue evaluation of the 15 material mixes shown above without completing millions of cycles of experimental fatigue loading, a fatigue model for ECC materials developed by Suthiwarapirak \& Matsumoto (2004) is used. This model, based on previous work by Zhang (1998) and Suthiwarapirak \& Matsumoto (2003), is shown as Equation 1.

$\frac{\sigma_{N}}{\sigma_{1}}=1-\left(0.025+1.5 \times \varepsilon_{t}\right) \log _{10}(N)$

where, $\sigma_{\mathrm{N}}$ is the maximum allowable flexural stress (i.e. fiber bridging stress) at the $\mathrm{N}$-th loading cycle, $\sigma_{1}$ is the material MOR, $\varepsilon_{\mathrm{t}}$ is a deformation parameter capturing the maximum tensile strain at a given load cycle, and $\mathrm{N}$ is the fatigue cycle count.

For Mixes 1, 2, and 3 of Table 1, flexural fatigue testing was carried out. Four point bending tests were

Table 2. Consumption and environmental impacts for individual mix designs.

\begin{tabular}{lllllll}
\hline Mix & $\begin{array}{l}\text { Total } \\
(\mathrm{MJ})\end{array}$ & $\begin{array}{l}\mathrm{CO}_{2} \\
(\mathrm{~g})\end{array}$ & $\begin{array}{l}\mathrm{NO}_{x} \\
(\mathrm{~g})\end{array}$ & $\begin{array}{l}\mathrm{PM}_{10} \\
(\mu \mathrm{g})\end{array}$ & $\begin{array}{l}\mathrm{SO}_{x} \\
(\mathrm{~g})\end{array}$ & $\begin{array}{l}\mathrm{BOD} \\
(\mathrm{g})\end{array}$ \\
\hline 1 & 6.69 & 669.7 & 3.55 & 5.88 & 2.62 & 0.21 \\
2 & 5.56 & 506.1 & 2.97 & 5.7 & 1.98 & 0.21 \\
3 & 4.95 & 416.3 & 2.63 & 5.75 & 1.63 & 0.21 \\
4 & 9.11 & 1228 & 4.46 & 9.5 & 2.82 & 0.16 \\
5 & 7.60 & 876.1 & 3.73 & 6.82 & 2.08 & 0.21 \\
6 & 6.03 & 634.6 & 3.04 & 4.63 & 1.56 & 0.21 \\
7 & 4.74 & 400.8 & 2.37 & 3.03 & 1.04 & 0.21 \\
8 & 4.74 & 400.8 & 2.37 & 3.03 & 1.04 & 0.21 \\
9 & 5.07 & 450.3 & 2.51 & 3.51 & 1.15 & 0.21 \\
10 & 5.49 & 572.9 & 2.873 & 3.74 & 1.42 & 0.21 \\
11 & 5.7 & 608.9 & 2.97 & 4.01 & 1.5 & 0.21 \\
12 & 5.7 & 614.7 & 2.86 & 4.53 & 1.5 & 0.21 \\
13 & 3.85 & 296.4 & 2.08 & 1.6 & 0.82 & 0.21 \\
14 & 5.04 & 476.3 & 2.59 & 3.29 & 1.21 & 0.21 \\
Concrete & 2.46 & 373.3 & 1.06 & 3.47 & 0.81 & 0 \\
\hline
\end{tabular}
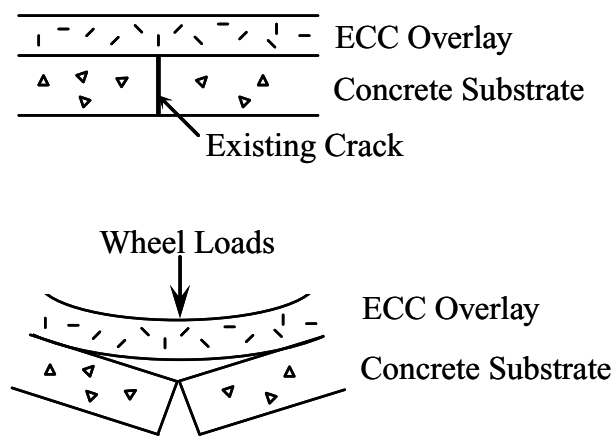

Figure 1. ECC overlay loading mechanism. 


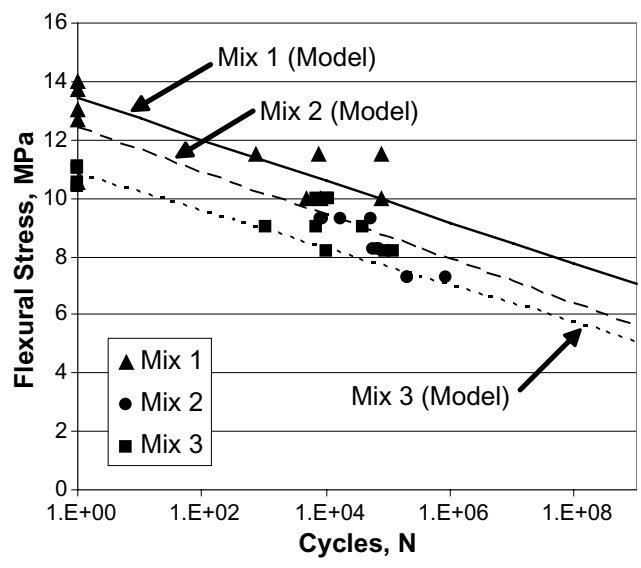

Figure 2. Comparison of experimental fatigue tests and predictive fatigue model.

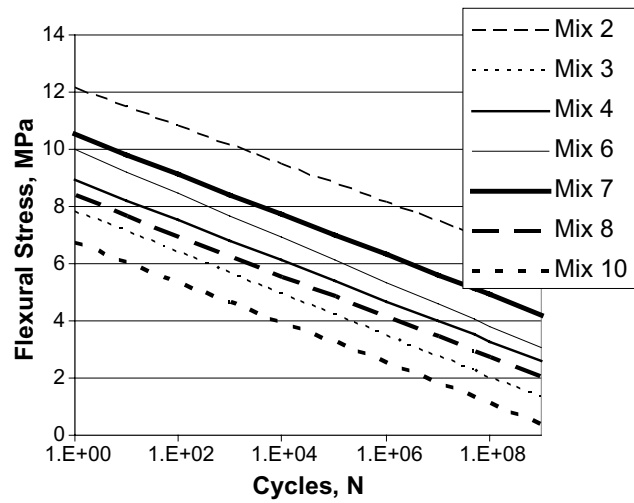

Figure 3. Fatigue degradation curves for a set of green ECC materials.

run as described in Qian (2007). The results of this fatigue testing and comparison with the above fatigue degradation model is shown in Figure 2. The fit with experimental data is sufficiently accurate among these three mix designs to apply to the larger population of ECC mixes shown in Table 1.

Using Equation 1, MOR values from Table 1, and measured tensile strain under bending load for each specimen, a family of S-N curves was developed for the green ECC mix designs. For clarity a small number of these curves are shown in Figure 3.

\section{DESIGN OF ECC OVERLAY}

To assess the impact of green ECC mix designs on the larger rigid pavement overlay system, a series of structural design charts were developed by Qian (2007) for concrete and ECC overlays. These structural design charts are based on FEM modeling of ECC and concrete overlaying a cracked concrete substrate. This is shown in Figure 4.

Using this model, a relationship between maximum stress developed during edge loading of a $1 \mathrm{ESAL}$ $(80 \mathrm{kN})$ dual axle load and overlay thickness was determined. Existing slab and subgrade parameters were held constant $\left(\mathrm{E}_{\text {existing }}=20.7 \mathrm{GPa}, \mathrm{k}_{\text {subgrade }}=\right.$ $27.1 \mathrm{MN} / \mathrm{m}^{3}$ ). The elastic modulus of the ECC overlay was also held constant at $20.7 \mathrm{GPa}$ for all mix designs. For the design of a concrete overlay, the elastic modulus was increased to $34.5 \mathrm{GPa}$.

From the FEM model, the following overlay design chart was developed, relating overlay design thickness with the maximum stress level in the overlay. This relationship is shown in Figure 5.

For validation of FEM results, maximum stresses in an uncracked substrate scenario were compared to the classical Westergaard solution for maximum tensile stress within a semi-infinite pavement slab under edge loading (Westergaard 1926). As the size of the slab within the FEM model increases, the maximum tensile stress within the system approaches the Westergaard solution asymptotically as expected.

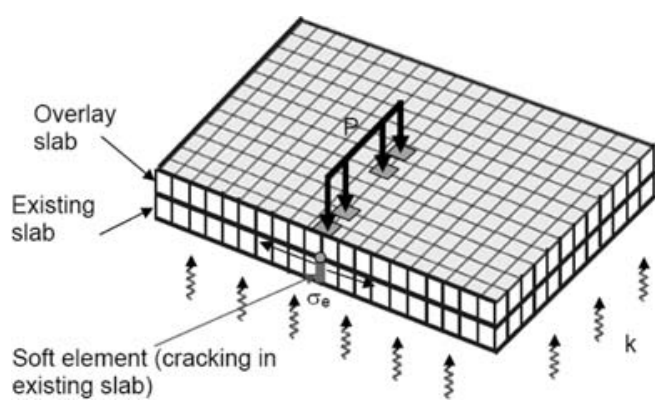

Figure 4. FEM model of overlay system with existing cracked concrete substrate.

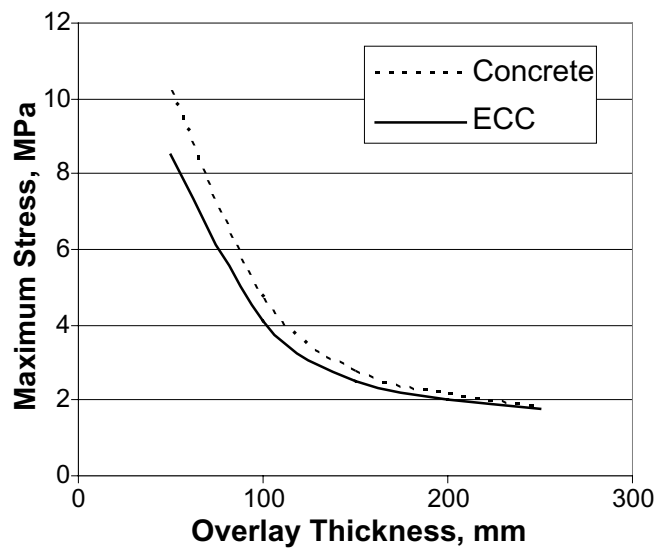

Figure 5. Design chart for overlay thickness. 


\section{OVERLAY APPLICATION ANALYSIS AND DESIGN}

As noted by Zapata \& Gambatese (2005), the overall environmental impacts of a specific overlay system are tied closely to the local application site, maintenance scheme, and traffic volume. For this research, an application site was chosen in southeast Michigan, near metropolitan Detroit. Interstate I-94 was selected. For pavement rehabilitation of site, the Michigan Department of Transportation typically would design a $175 \mathrm{~mm}-200 \mathrm{~mm}$ thick unbonded concrete overlay with a predicted service life of 20 years (MDOT 2005). Average daily truck traffic for the selected site is 12,000 with an assumed annual traffic growth rate of $5 \%$. Over the 20 year service life, this results in approximately $5 \times 10^{7}$ equivalent single axle loads. For this analysis, all overlay systems (concrete and ECC) are designed to last an equivalent lifetime of 20 years.

Using the fatigue degradation curves shown in Figure 3 (in addition to those for ECC mix designs not shown in Figure 3) the maximum flexural stress allowable with the ECC material can be determined. The maximum allowable flexural stress is shown for each ECC mix design in Table 3.

Using this maximum overlay stress, the minimum design overlay thickness can be calculated from Figure 5. The calculated minimum overlay design thicknesses for each of the 14 ECC mix designs and a concrete overlay are also shown in Table 3. As seen, as the fatigue performance of a specific ECC mix falls, the required overlay thickness increases to reduce the maximum tensile stress level within the overlay. This is most apparent with ECC Mix 10, which requires an overlay thickness of over $280 \mathrm{~mm}$.

Table 3. Computed fatigue stress at $5 \times 10^{7}$ loading cycles and required overlay thickness.

\begin{tabular}{llc}
\hline Mix & $\begin{array}{l}\text { Stress at } 5 \times 10^{7} \\
\text { Cycles (MPa) }\end{array}$ & $\begin{array}{l}\text { Overlay Thickness } \\
(\mathrm{mm})\end{array}$ \\
\hline 1 & 8.02 & 52 \\
2 & 7.01 & 59 \\
3 & 5.42 & 76 \\
4 & 7.01 & 59 \\
5 & 2.42 & 168 \\
6 & 3.50 & 117 \\
7 & 4.23 & 91 \\
8 & 5.12 & 81 \\
9 & 2.70 & 151 \\
10 & 1.43 & 282 \\
11 & 5.12 & 81 \\
12 & 3.23 & 127 \\
13 & 4.04 & 102 \\
14 & 2.96 & 138 \\
Concrete* & 2.3 & 180 \\
\hline
\end{tabular}

* Concrete overlay stress level determined through fatigue testing results.

\section{ENVIRONMENTAL METRICS}

From this design, the overall environmental performance of the overlay design can be evaluated. Comparing trends within Tables 2 and 3, a tradeoff between lower material environmental impact and greater overlay thickness is apparent in some cases. To best compare these design alternatives, comparisons between the $14 \mathrm{ECC}$ and one concrete overlay material are made on an "installed" basis.

For this study, the width of the highway is assumed to be $7.32 \mathrm{~m}$ and the length of the project is $1000 \mathrm{~m}$. Using the resource consumption and environmental impacts per volume of material shown in Table 2 and the minimum required overlay thicknesses from Table 3, the resource consumption and environmental impacts per kilometer of overlay installed are shown in Table 4 (for an overlay with 20 year service life).

As seen, the tradeoff between material performance and actual resource consumption or environmental impact can result in seemingly "greener" materials producing higher overall system impact. Once again, Mix 10 demonstrates this finding most clearly. Although Mix 10 exhibits significant environmental improvements over other ECC mix designs, its lower mechanical performance requires a much higher overlay thickness, resulting in an overall greater environmental impact per kilometer of overlay constructed. The best overlay material, considering primary energy, from the group developed is Mix 2. When considering $\mathrm{CO}_{2}$ emissions, Mix 2 is also the best option. However, the significant non-linearity of these results with regard to other impact categories highlights the difficult decisions confronting transportation designers and government agencies.

Table 4. Resource consumption and environmental impact of overlay materials per kilometer installed.

\begin{tabular}{lrlllrr}
\hline & $\begin{array}{l}\text { (MJ) } \\
\text { Mix }\end{array}$ & $\begin{array}{l}\mathrm{CO}_{2} \\
(\mathrm{~kg})\end{array}$ & $\begin{array}{l}\mathrm{NO}_{x} \\
(\mathrm{~kg})\end{array}$ & $\begin{array}{l}\mathrm{PM}_{10} \\
(\mathrm{mg})\end{array}$ & $\begin{array}{r}\mathrm{SO}_{x} \\
(\mathrm{~kg})\end{array}$ & $\begin{array}{l}\mathrm{BOD} \\
(\mathrm{kg})\end{array}$ \\
\hline 1 & 2,538 & 254,056 & 1,347 & 2,231 & 994 & 80 \\
2 & 2,407 & 219,121 & 1,286 & 2,468 & 857 & 90 \\
3 & 2,759 & 232,027 & 1,466 & 3,205 & 908 & 117 \\
4 & 3,947 & 532,005 & 1,932 & 4,115 & 1,222 & 69 \\
5 & 9,346 & $1,077,328$ & 4,587 & 8,387 & 2,558 & 258 \\
6 & 5,163 & 543,362 & 2,603 & 3,964 & 1,336 & 180 \\
7 & 3,373 & 285,229 & 1,687 & 2,156 & 740 & 149 \\
8 & 2,794 & 236,226 & 1,397 & 1,786 & 613 & 124 \\
9 & 5,612 & 498,417 & 2,778 & 3,885 & 1,273 & 232 \\
10 & 11,320 & $1,181,232$ & 5,924 & 7,712 & 2,928 & 433 \\
11 & 3,360 & 358,880 & 1,751 & 2,363 & 884 & 124 \\
12 & 5,280 & 569,404 & 2,649 & 4,196 & 1,390 & 195 \\
13 & 2,863 & 220,453 & 1,547 & 1,190 & 610 & 156 \\
14 & 5,086 & 480,704 & 2,614 & 3,320 & 1,221 & 212 \\
Concrete & 3,241 & 491,834 & 1,397 & 4,572 & 1,067 & - \\
\hline & & & & & &
\end{tabular}


This analysis does not include the impacts of required life cycle maintenance, changing surface roughness, and end-of-life scenarios of these overlay systems as addressed by Zhang et al (2007). While greatly complicating the analysis, this more complete analysis will be undertaken in the future.

\section{CONCLUSION}

The use of greener cementitious materials for repair and rehabilitation of rigid pavement systems represents significant potential for the reduction of material and energy resource consumption and pollutant emissions. Additionally, the incorporation of industrial waste streams into new overlay materials can successfully divert large waste flows from landfills. However, the incorporation of such industrial wastes must be carefully controlled to maintain overall system performance over the entire design life cycle.

Presented within this paper is a novel integrated approach to materials and structures design that leverages materials greening and structural design to rehabilitate existing rigid pavements. The results of this are a potential reduction of primary energy use and $\mathrm{CO}_{2}$ emissions by $21 \%$ and $55 \%$ respectively. Findings from this study can be used by highway engineers and government agencies to systematically guide future rigid pavement rehabilitation projects toward lower resource consumption and pollution emissions.

\section{ACKNOWLEDGEMENTS}

The authors would like to thank the US National Science Foundation MUSES Grant (CMS-0223971 and CMS-0329416) for funding this research.

\section{REFERENCES}

Chen, A., Keoleian, G.A., Gabler, E. 2007. Evaluation of Life-Cycle Cost Analysis Practices Used by the Michigan Department of Transportation. Submitted to Journal of Transportation Engineering.

ERES Consultants, Inc. 1999. NCHRP Report 415, Evaluation of Unbonded Portland Cement Concrete Overlays, Transportation Research Board, Washington, D.C.

Horvath, A., Hendrickson, C. 1998. Comparison of Environmental Implications of Asphalt and Steel-Reinforced Concrete Pavements. Transportation Research Record. 1626 (1) 105.

Huang, Y.H. 2004. Pavement Analysis and Design, 2nd edition, Pearson Education, Upper Saddle River, NJ 07458 .
Kamada, T. \& Li, V.C. 2000. The Effects of Surface Preparation on the Fracture Behavior of ECC/Concrete Repair System, J. of Cement and Concrete Composites, 22(6), 423-431.

Lepech, M.D., Li, V.C. \& Keoleian, G.A. 2005. Sustainable Infrastructure Material Design, In Nowak and Frongopol (eds) Proceedings of The 4th International Workshop on Life-Cycle Cost Analysis and Design of Civil Infrastructures Systems, Cocoa Beach, Florida, May 8-11 2005, 83-90.

Lepech, M.D., Li, V.C., Roberston, R.E., Keoleian, G.A. 2007. Design of Green Cementitious Composites for Improved Sustainability. Submitted to ACI Materials Journal.

Li, V.C. 2003. On Engineered Cementitious Composites (ECC) - A Review of the Material and its Applications, J. Advanced Concrete Technology, 1(3) 215-230.

Lim, Y.M. \& Li, V.C. 1997. Durable Repair of Aged Infrastructures Using Trapping Mechanism of ECC, J. of Cement and Concrete Composites, 19(4), 373-385.

Michigan Department of Transportation. 2005. Pavement Design and Selection Manual Lansing, Michigan USA.

Portland Cement Association. 2007. http://www.cement.org/ market/ (accessed on 12/6/07).

Qian, S. 2007. Influence of Concrete Material Ductility on the Behavior of High Stress Concentration Zones. Ph. D. Thesis. University of Michigan, Ann Arbor.

vanOss, H. 2007. Mineral Commodity Summaries: Cement. United States Geological Survey. Reston, VA USA.

Suthiwarapirak, P., Matsumoto, T. 2003. Fiber Bridging Degradation Based Fatigue Analysis of ECC under Flexure Journal of Applied Mechanics, JSCE, 6. 1179-1188.

Suthiwarapirak, P., Matsumoto, T. 2004. 3D Fatigue Analysis of RC Bridge Slabs and Slab Repairs by Fiber Cementitious Materials. In V.C. Li et al (eds) Proceedings of Fracture Mechanics of Concrete Structures 5. Vail, Colorado USA April 12-16 2004.

Tayabji, S.D. \& Okamoto, P.A., 1985. Thickness Design of Concrete Resurfacing, Proc., 3rd Int'l Conf. on Concrete Pavement Design and Rehabilitation, 367-379.

Westergaard, H. 1926. Stresses in Concrete Pavements Computed by Theoretical Analysis. Public Roads. Vol. 7. pp. 25-35.

Zapata, P. \& Gambatese, J. 2005. Energy consumption of asphalt and reinforced concrete pavement materials and construction. Journal of Infrastructure Systems, 11(1) 9-20.

Zhang, H., Lepech, M.D. \& Keoleian, G.A. 2007. Dynamic Life Cycle Modeling of Pavement Overlay System: Capturing the Impacts of Users, Construction, and Roadway Deterioration. Submitted to Journal of Transportation Engineering.

Zhang, J. 1998. Fatigue Fracture of Fiber Reinforced Concrete-An Experimental and Theoretical Study. Ph. D. Thesis, Department of Structural Engineering and Materials, Technical University of Denmark.

Zhang J. \& Li, V.C., 2002. Monotonic \& Fatigue Performance in Bending of Fiber Reinforced ECC in Overlay System, J. of Cement and Concrete Research, 32(3), 415-423. 